\title{
Trials, registries and guidelines for non-ST-elevation acute coronary syndromes
}

\author{
F. W. A. Verheugt
}

Published online: 21 November 2013

(C) The Author(s) 2013. This article is published with open access at Springerlink.com

The most common admission indication in cardiology practice is acute coronary syndrome with or without ST-segment elevation. In patients presenting with ST-segment elevation at admission, ECG reperfusion therapy is instituted as fast as possible [1-3], which can be accomplished by primary PCI, by fibrinolysis, or both. This results in a significant reduction in infarct size and improvement of short- and long-term prognosis $[2,3]$. In patients with coronary syndromes presenting without ST-segment elevation on the admission ECG, antiischaemic and antithrombotic therapies are also of utmost importance. However, in the last decade a strong switch has been seen in the invasive approach to this condition. Angiography can improve risk stratification and, if indicated, revascularisation can be planned. Several randomised trials have evaluated a routine invasive strategy in comparison to a more selective invasive approach in these patients. The outcome results were mixed [4-6]. Although these meta-analyses included trials from the pre-clopidogrel era, a routine invasive strategy showed a reduction in myocardial infarction and repeat intervention. The results with regard to early and long-term survival were also variable. There seemed to be an early hazard for early mortality compensated by a later reduction [4].

The substrate of a non-ST-elevation myocardial infarction does not usually consist of an acutely occluded epicardial coronary artery as in ST-segment-elevation myocardial infarction. In non-ST-elevation acute coronary syndromes (NSTE-ACS) there can be severe but non-occlusive coronary artery disease, or no disease at all. In the large TACTICS-TIMI-18 study nearly half of the patients had left main or triple vessel disease and

F. W. A. Verheugt $(\bowtie)$

Department of Cardiology, Onze Lieve Vrouwe Gasthuis (OLVG),

PO Box 95500, 1090 HM Amsterdam, the Netherlands

e-mail: f.w.a.verheugt@olvg.nl only $13 \%$ had normal coronary arteries [7]. In both instances reperfusion therapy is not indicated and only leads to harm by bleeding and excess myocardial infarction $[8,9]$.

The cornerstone of the treatment of patients undergoing coronary stenting for acute coronary syndromes is dual antiplatelet therapy with aspirin and the platelet $\mathrm{P}_{2} \mathrm{Y}_{12}$ receptor antagonist clopidogrel. Consequently, many patients in cardiology practice in 2013 are on dual antiplatelet therapy, mainly aspirin and clopidogrel. The only important side effect of dual antiplatelet therapy is increased bleeding in comparison with aspirin alone. This has been established in the large trials with clopidogrel in ACS $[10,11]$ and thereafter [12], also in atrial fibrillation [13]. Especially in the latter dual antiplatelet therapy has shown to be as hazardous as oral anticoagulation [14]. The novel platelet $\mathrm{P}_{2} \mathrm{Y}_{12}$ receptor antagonists prasugrel and ticagrelor are more effective than clopidogrel in patients, but show more major bleeding including intracranial haemorrhage [15, 16]. Prasugrel is specifically indicated and registered for use after PCI for ACS.

In today's issue of the Netherlands Heart Journal, the design of a study on adherence to evidence-based medicine in a large group of patients discharged after ACS is described [17]. The strength of the paper is that the study is (a) carried out in a large single region, (b) prospective in nature and (c) part of a thorough registry. In this registry the new oral antiplatelet drug prasugrel will be used. The interim results of this study are now available online and will be published in a forthcoming edition of the journal [18].

Of course, the weakness of the registry is the potential confounding bias, which is inherent to every registry, even the prospective ones. A randomised comparison with e.g. ticagrelor or even clopidogrel would, therefore, be preferable, but randomised controlled trials have the severe shortcoming 
Table 1 Shortcomings of randomised trials, meta-analyses, registries and guidelines

\begin{tabular}{ll}
\hline Method & Shortcomings \\
\hline Randomised trial & $\begin{array}{l}\text { Selection bias } \\
\text { Poor generalisibility } \\
\text { Meta-analysis }\end{array}$ \\
& $\begin{array}{l}\text { Publication bias } \\
\text { Overestimation of treatment effect } \\
\text { Often considerable heterogeneity }\end{array}$ \\
Registry & Confounding bias \\
Guideline & Meta-analyses used as high level of evidence
\end{tabular}

of selection bias (Table 1). For a long time now, meta-analyses have been used to evaluate treatment effects of certain medical strategies in a broader perspective. However, meta-analyses not only suffer from publication bias and, therefore, may overestimate a treatment effect, they often also show considerable heterogeneity. Unfortunately, many guidelines appreciate meta-analyses as level of evidence similar to that of individual randomised controlled trials. Given the above, this must be discouraged. At best, meta-analyses are hypothesis generating, and should not be used to underscore the weight of a cluster of individual randomised trials. Even in the absence of properly randomised studies with enough power, metaanalyses should be omitted from guidelines when it comes to weighing level of evidence. Both randomised studies and registries for medical procedures are of the utmost importance. Although clinical trialists despise observational studies because of the confounding factors, they should admit that they represent the real world provided all incident NSTE-ACS cases are entered into the registries For that purpose, only prospective registries are acceptable for therapy evaluation. The current design paper meets this criterion.

In conclusion, the design of a registry presented in this issue is a solid basis for the collection of evidence-based discharge strategies after ACS. However, a new antiplatelet drug will be used in the registry for the patients treated with PCI for their index ACS. This may be a confounded registry, in that prasugrel can be used exclusively in patients without contraindications to the agent (age, prior stroke and low body weight). In that case clopidogrel or ticagrelor may be preferred. And hopefully pre-treatment with prasugrel will be avoided, since it is not helpful and causes increased bleeding [19]. But given the excellent past clinical performance of the study group it will implement the most recent study data into their practice.

Conflict of interest The author reports in relation to this article consulting fees from Lilly/Daiichi Sankyo, as well as speaker's honoraria from AstraZeneca and Sanofi-Aventis.
Open Access This article is distributed under the terms of the Creative Commons Attribution License which permits any use, distribution, and reproduction in any medium, provided the original author(s) and the source are credited.

\section{References}

1. Verheugt FWA. Reperfusion therapy starts in the ambulance. Circulation. 2006;113:2377-9.

2. Keeley EC, Boura JA, Grines CL. Comparison of primary and facilitated percutaneous coronary intervention for ST-elevation myocardial infarct: quantitative review of randomized trials. Lancet. 2006;367:579-88.

3. Fibrinolytic Therapy Trialists' Collaborative Group. Indications for fibrinolytic therapy in suspected acute myocardial infarction: collaborative overview of early mortality and major morbidity results from all randomised trials of more than 1000 patients. Fibrinolytic Therapy Trialists' (FTT) Collaborative Group. Lancet. 1994;343:311-22.

4. Mehta SR, Cannon CP, Fox KAA, et al. Routine versus selective invasive strategies in patients with acute coronary syndromes: a collaborative meta-analysis of randomized trials. JAMA. 2005;293: 2908-17.

5. Qayyum R, Khalid R, Adomaityte J, et al. Systematic review: comparing routine and selective invasive strategies for the acute coronary syndrome. Ann Intern Med. 2008;148:186-96.

6. Fox KA, Clayton TC, Damman P, et al. Long-term outcome of a routine versus selective invasive strategy in patients with non-STsegment elevation acute coronary syndrome a meta-analysis of individual patient data. J Am Coll Cardiol. 2010;55:2435-45.

7. Cannon CP, Weintraub WS, Demopoulos LA, et al. Comparison of early invasive and conservative strategies in patients with unstable coronary syndromes treated with the glycoprotein IIb/IIIa inhibitor tirofiban. N Engl J Med. 2001;344:1879-87.

8. Antman EM, McCabe CH, Gurfinkel EP, et al. Enoxaparin prevents death and cardiac ischemic events in unstable angina/non-Q wave myocardial infarction. Results of the TIMI 11B trial. Circulation. 1999;100:1593-601.

9. Bar FW, Verheugt FW, Col J, et al. Thrombolysis in patients with unstable angina improves the angiographic, but not the clinical outcome. Results of UNASEM, a multicentre, randomised, placebo controlled clinical trial with anistreplase. Circulation. 1992;86:131-7.

10. Investigators CURE. Effect of clopidogrel in addition to aspirin in patients with acute coronary syndromes without ST-segment elevation. N Engl J Med. 2001;345:494-502.

11. COMMIT (Clopidogrel and Metoprolol in Myocardial Infarction Trial) Collaborative Group. Addition of clopidogrel to aspirin in 45,852 patients with acute myocardial infarction: randomised placebo-controlled trial. Lancet. 2005;366:160721.

12. Bhatt DL, Fox KAA, Hacke W, et al. Clopidogrel and aspirin versus aspirin alone for the prevention of atherothrombotic events. N Engl J Med. 2006;354:1706-17.

13. ACTIVE investigators. Clopidogrel plus aspirin versus oral anticoagulation for atrial fibrillation in the Atrial fibrillation Clopidogrel Trial with Irbesartan for prevention of Vascular Events (ACTIVE W): a randomised controlled trial. Lancet. 2006;367: 1903-12.

14. Verheugt FWA. Good old warfarin for stroke prevention in atrial fibrillation. Lancet. 2006:367:1877-8. 
15. Wallentin L, Becker RC, Budaj A, et al. Ticagrelor versus clopidogrel in patients with acute coronary syndromes. N Engl J Med. 2009;361: 1045-57.

16. Wiviott SD, Braunwald E, McCabe $\mathrm{CH}$, et al. Prasugrel versus clopidogrel in patients with acute coronary syndromes. N Engl J Med. 2007;357:2001-15.

17. Yetgin T, van der Linden MMJM, De Vries AG, et al. Adoption of prasugrel into routine practice: rationale and design for the Rijnmond Collective Cardiology Research (CCR) study in percutaneous coronary intervention for acute coronary syndromes. Neth Heart J 2013. doi:10.1007/s12471-013-0472-1.

18. Yetgin T, van der Linden MMJM, De Vries AG, et al. Current discharge management of acute coronary syndromes: data from the Rijnmond Collective Cardiology Research (CCR) study. Neth Heart J 2013. doi:10.1007/s12471-013-0484-X.

19. Montalescot G, Bolognese L, Dudek D, et al. Pretreatment with prasugrel in non-ST-elevation acute coronary syndromes. N Engl J Med. 2013;369:999-1010. 